\title{
Safety, Acceptability, and Feasibility of Early Infant Male Circumcision Conducted by Nurse-Midwives Using the AccuCirc Device: Results of a Field Study in Zimbabwe
}

\author{
Webster Mavhu, a,b Natasha Larke, ${ }^{c}$ Karin Hatzold, ${ }^{d}$ Getrude Ncube, ${ }^{e}$ Helen A Weiss, ${ }^{c}$ \\ Collin Mangenah, ${ }^{a}$ Prosper Chonzi, ${ }^{f}$ Owen Mugurungi, ${ }^{e}$ Juliet Mufuka, ${ }^{a}$ Christopher A Samkange, ${ }^{g}$ \\ Gerald Gwinji, ${ }^{e}$ Frances M Cowan, ${ }^{a, b}$ Ismail Ticklayg
}

Early infant male circumcision (EIMC) conducted by nurse-midwives using the AccuCirc device proved safe, feasible, and acceptable to parents in Zimbabwe. The AccuCirc device has the potential to facilitate widespread scale-up of safe EIMC in sub-Saharan Africa.

\section{ABSTRACT}

Background: For prevention of HIV, early infant male circumcision (EIMC) needs to be scaled up in countries with high HIV prevalence. Routine EIMC will maintain the HIV prevention gains anticipated from current adult male circumcision initiatives. We present here the results of a field study of EIMC conducted in Zimbabwe.

Methods: The study was observational and based on the World Health Organization (WHO) framework for clinical evaluation of male circumcision devices. We recruited parents of newborn male infants between August 2013 and July 2014 from 2 clinics. Nurse-midwives used the AccuCirc device to circumcise eligible infants. We followed participants for 14 days after EIMC. Outcome measures were EIMC safety, acceptability, and feasibility.

Results: We enrolled 500 male infants in the field study (uptake 11\%). The infants were circumcised between 6 and 60 days postpartum. The procedure took a median of 17 minutes (interquartile range of 5 to 18 minutes). Mothers' knowledge of male circumcision was extensive. Of the 498 mothers who completed the study questionnaire, $91 \% \mathrm{knew}$ that male circumcision decreases the risk of HIV acquisition, and $83 \%$ correctly stated that this prevention is partial. Asked about their community's perception of EIMC, $40 \%$ felt that EIMC will likely be viewed positively in their community; $13 \%$ said negatively; and $47 \%$ said the perception could be both ways. We observed 7 moderate or severe adverse events (1.4\%; $95 \%$ confidence interval, $0.4 \%$ to $2.4 \%$ ). All resolved without lasting effects. Nearly all mothers (99\%) reported great satisfaction with the outcome, would recommend EIMC to other parents, and would circumcise their next sons. Conclusion: This first field study in sub-Saharan Africa of the AccuCirc device for EIMC demonstrated that EIMC conducted by nurse-midwives with this device is safe, feasible, and acceptable to parents.

\section{INTRODUCTION}

E arly infant male circumcision (EIMC) is simpler and less costly than voluntary medical male circumcision

\footnotetext{
${ }^{a}$ Centre for Sexual Health and HIV/AIDS Research (CeSHHAR), Harare, Zimbabwe.

${ }^{b}$ University College London, London, United Kingdom.

'London School of Hygiene \& Tropical Medicine, London, United Kingdom.

d Population Services International, Harare, Zimbabwe.

${ }^{\mathrm{e}}$ Ministry of Health and Child Care, Harare, Zimbabwe.

${ }^{f}$ Harare City Health, Harare, Zimbabwe.

g University of Zimbabwe College of Health Sciences, Harare, Zimbabwe.

Correspondence to Karin Hatzold (khatzold@psi-zim.co.zw)
}

(VMMC). ${ }^{1-3}$ Also, EIMC is likely to prevent HIV acquisition more effectively than VMMC; EIMC is carried out long before an individual becomes sexually active and thus avoids the risk associated with sex during the healing period. ${ }^{4}$ In order for EIMC to maintain the HIV prevention gains anticipated through VMMC, it should be suitable for safe and efficient implementation in lowresource settings. Since large-scale EIMC has never been practiced in Southern Africa, demonstration of its safety, acceptability, and feasibility in this setting is crucial.

A number of circumcision devices are used with infants, including the Mogen clamp, Gomco clamp, and 
Plastibell. $^{5}$ Each of these devices is associated with rare but potentially serious complications. Circumcision using the Mogen clamp can result in partial or total amputation of the glans penis or removal of too little foreskin (in which case the remaining foreskin remains vulnerable to infection with HIV)..$^{5-8}$ A mismatch in sizes of the separate pieces of the Gomco clamp can result in laceration of the glans penis. ${ }^{5,9}$ Proximal migration of the Plastibell during circumcision can result in necrosis of the glans and other injuries; this risk is increased if the incorrect size of "bell" is used. ${ }^{5,10-12}$

AccuCirc, a relatively new EIMC device (introduced in 2008), comes preassembled and thus may have the potential to address some of these shortcomings. ${ }^{3,13}$ In addition, it has a shielding ring that protects the glans penis, preventing laceration or amputation. ${ }^{3,9,13}$ The AccuCirc device is also disposable and does not require sterilization. These factors make it appealing for use in sub-Saharan Africa, particularly where health centers lack electricity and sterilization equipment. ${ }^{3,9}$ However, before AccuCirc is used to roll out EIMC in sub-Saharan Africa, further evidence is needed on its performance in comparison with other methods of EIMC.

Although the World Health Organization (WHO) has determined that it will not prequalify medical devices for EIMC, the WHO "Framework for Clinical Evaluation of Devices for Male Circumcision" $^{\prime 14}$ provides a useful and valid guide for evaluating novel EIMC devices for safety, acceptability, and feasibility. The guide recommends that, for innovative male circumcision methods, at least 3 successive studies be conducted in countries of intended use: a case series, a comparative trial, and a field study. ${ }^{14}$ Two studies to determine the safety, acceptability, and cost of the AccuCirc device in sub-Saharan Africa have been conducted in Botswana and Zimbabwe., ${ }^{3,9,13}$ In line with the WHO framework, Zimbabwe also conducted a field study of the AccuCirc device in which nurse-midwives performed EIMC. Here, we present the findings of this field study on safety, acceptability, and feasibility of the AccuCirc device for EIMC. Study findings will inform EIMC scale-up in Zimbabwe and the wider region.

\section{METHODS}

\section{Study Design}

The field study was observational. As the WHO

"Framework for Clinical Evaluation of Devices for
Male Circumcision"14 ${ }^{14}$ recommends, we enrolled, circumcised, and followed 500 participants. Participants were circumcised using the AccuCirc device and followed for 2 weeks post-circumcision.

\section{Recruitment and Training of EIMC Providers}

In August and September 2013, doctors trained 4 study nurse-midwives over the course of 5 days to use the AccuCirc device. The trainers had previously performed circumcisions for the Zimbabwe EIMC comparative trial, described in detail elsewhere. ${ }^{3,13}$ The training curriculum consisted of didactic lectures, practical skill sessions, use of an EIMC anatomic model, written assessment, and practice evaluation. Trainees were required to score $100 \%$ on the written assessment and show competency using the anatomic model. Each provider then had to demonstrate competency performing 10 supervised circumcisions with the AccuCirc device.

\section{Participants}

Mothers and infants were enrolled between Before AccuCirc is August 2013 and July 2014 at Edith Opperman used to roll out and Mabvuku, 2 polyclinics in Harare, with 400 EIMC in suband 250 deliveries per month, respectively. ${ }^{15}$ Saharan Africa, Women attending the clinic were informed of further evidence EIMC and enrolled at the antenatal clinic and after delivery in the maternity ward. In the community, we used educational materials (posters and pamphlets) and demand-creation activities (sensitization shows, dramas, and group and person-to-person discussions) to educate people about the field study. Before discharge postdelivery, mothers who were interested in having their male infants circumcised were asked to (1) provide locator information and consent for an outreach worker to physically verify their address, (2) complete an intervieweradministered questionnaire (asking, among other questions, about sociodemographic information and knowledge about HIV and male circumcision), and (3) discuss the procedure with the infant's father (if available) before attending for EIMC at their first postnatal visit.

We collected data on eligibility criteria from all mothers and infants. Maternal eligibility criteria were: (1) ability to attend follow-up appointments at the study clinic through 2 weeks postpartum, (2) readiness to provide a home address, and (3) written informed consent. Only infants ages 6 to 60 days were eligible. Although WHO guidelines ${ }^{5}$ state that infants can be 
circumcised as early as 12 to 24 hours old, we waited for 6 days to be sure that all body systems were stable and any immediate postpartum infant mortality would not be erroneously ascribed to EIMC. Additional infant eligibility criteria were: (1) male, (2) gestational age $\geq 37$ weeks, (3) birth weight $\geq 2,500$ grams, (4) no evidence of neonatal infection/sepsis or other illness requiring hospitalization, (5) no family history of bleeding disorder, and (6) no genital abnormality constituting a contraindication to EIMC. Between recruitment and enrollment, an outreach worker visited homes to verify the addresses of all potential field study participants.

\section{Intervention}

Before enrollment, study staff performed a physical examination to exclude infants with abnormalities precluding circumcision. We referred to a specialist all 10 infants who were ineligible due to genital abnormalities. The 4 trained nursemidwives ( 2 at each study clinic) performed all the circumcisions, assisted by 2 registered general nurses. To minimize bleeding, all infants received vitamin $\mathrm{K}$ ( $1 \mathrm{mg}$ ) an hour before the procedure. Additionally, all infants had approximately 1 gram of EMLA Cream (eutectic mixture of local anesthetics containing $2.5 \%$ lidocaine and $2.5 \%$ prilocaine) applied to the outer foreskin and shaft of the penis about 45 minutes before the procedure. Administration of vitamin $\mathrm{K}$ and the anesthetic is part of standard operating procedures for conducting EIMCs and not specific to the AccuCirc device.

We assessed achievement of anesthetic effect by holding the foreskin using artery forceps. If there was no pain response from the infant, subsequent steps would commence. Otherwise, providers would wait until the EMLA Cream had achieved anesthetic effect (an additional 10 to 15 minutes). When the EMLA Cream had achieved anesthetic effect, the surgical area was cleaned with povidone-iodine. Physiologic adhesions between the foreskin and the glans were released by manual technique using the flexible foreskin probe that comes with the AccuCirc kit. The nurse-midwife then marked the circumcision site (around the corona) with a surgical pen that is also part of each AccuCirc kit. The pen mark helps to minimize excessive or insufficient skin removal.

In addition to the flexible foreskin probe, the AccuCirc device consists of a shielding ring plus a single-action clamp (i.e., can be used only once) that contains a circular blade. It is available in
2 sizes: $1.1 \mathrm{~cm}$ and $1.3 \mathrm{~cm}$ (penile diameter). ${ }^{9}$ The nurse-midwives performed EIMC using AccuCirc following manufacturer's recommendations (www.accucirc.com) and as recommended by the study previously conducted in Botswana.' During the procedure, glucose water was given to the infant using a gloved finger, as has been recommended for pain management for neonatal circumcision. ${ }^{15,17,18}$ After the procedure, the circumcision wound was dressed, and infants were checked for post-procedure bleeding or other immediate complications. Nurse-midwives gave mothers detailed post-procedure care instructions (how to deal with dressing, bleeding, and signs of infection) and emergency contact information. Nurse-midwives also encouraged mothers to phone the nurse-coordinator or to come to the clinic if they had any worries or if unanticipated events occurred between scheduled visits.

\section{Follow-up and Evaluation}

Follow-up appointments at the clinic took place at days 2, 7, and 14 after circumcision. At these visits, nurse-midwives asked parents about complications. The EIMC providers also conducted physical examinations of the infants, including inspection of the circumcision site. Seven days after the procedure we asked parents their views on the acceptability of circumcision.

\section{Outcome Measures}

Outcome measures for the field study were (1) EIMC safety, (2) acceptability, and (3) feasibility. Safety was indicated by the number of moderate and severe adverse events (AEs). EIMCrelated AEs were categorized as bleeding, infection, inadequate or excessive skin removal, or penile injury (glans, urethra, or shaft) (Table 1). We recorded minor events such as bleeding that could be stopped with simple compression, but excluded them from analyses. We measured EIMC acceptability by the proportion of parents who (1) adopted EIMC for their sons, (2) reported being satisfied with the procedure, and (3) expressed willingness to adopt EIMC for a future son.

We asked parents to rate their satisfaction with and acceptability of the procedure on a numerical scale ranging from 0 (dissatisfaction) to 10 (very satisfied). Satisfaction was defined as a score between 6 and 10. We also asked parents to rate on a scale of 0 to 10 the likelihood that they would recommend EIMC to friends or relatives. A score of 0 was classified as “would 
TABLE 1. Classification of Procedure-Related Moderate and Severe Adverse Events

\begin{tabular}{|c|c|c|}
\hline & Moderate & Severe \\
\hline Bleeding & $\begin{array}{l}\text { Bleeding that is not controlled by new } \\
\text { dressings or } 5 \text { to } 10 \text { minutes of manual } \\
\text { pressure and requires a special return to the } \\
\text { clinic for a pressure dressing, additional skin } \\
\text { sutures, or additional vitamin } \mathrm{K} \text { administration } \\
\text { without surgical re-exploration of the wound. }\end{array}$ & $\begin{array}{l}\text { Bleeding that requires surgical re-exploration, } \\
\text { hospitalization, or transfer to another facility, } \\
\text { or any case where blood transfusion or } \\
\text { intravenous fluid is necessary. }\end{array}$ \\
\hline Infection & $\begin{array}{l}\text { Discharge from the wound, painful swelling } \\
\text { with erythema or elevated temperature, } \\
\text { or use of oral antibiotics. }\end{array}$ & $\begin{array}{l}\text { Cellulitis or abscess of the wound, or infection } \\
\text { severe enough to require surgical intervention, } \\
\text { hospitalization, or intravenous or } \\
\text { intramuscular antibiotic therapy. }\end{array}$ \\
\hline $\begin{array}{l}\text { Inadequate } \\
\text { skin } \\
\text { removal }\end{array}$ & $\begin{array}{l}\text { Prepuce partially covers glans when flaccid } \\
\text { but surgical correction is not necessary. }\end{array}$ & $\begin{array}{l}\text { Prepuce partially covers glans when flaccid } \\
\text { and immediate surgical correction is } \\
\text { necessary. }\end{array}$ \\
\hline $\begin{array}{l}\text { Excessive } \\
\text { skin } \\
\text { removal }\end{array}$ & $\begin{array}{l}\text { Tightness of the skin discernible, and } \\
\text { additional sutures or skin mobilization } \\
\text { needed for wound closure, but no other } \\
\text { intervention needed. }\end{array}$ & $\begin{array}{l}\text { Reoperation or referral/transfer to } \\
\text { another facility required. }\end{array}$ \\
\hline $\begin{array}{l}\text { Penile } \\
\text { injury }\end{array}$ & $\begin{array}{l}\text { Significant laceration requiring either } \\
\text { prolonged follow-up, care, and attention or } \\
\text { repeated or additional dressings. }\end{array}$ & $\begin{array}{l}\text { Significant injury including laceration } \\
\text { or severed portion of glans, damage to } \\
\text { the urethra, or laceration of the shaft } \\
\text { with ongoing bleeding that requires } \\
\text { hospitalization, transfer, or transfusion. }\end{array}$ \\
\hline
\end{tabular}

not recommend" and 10 as "would definitely recommend." Feasibility was defined as spending the least amount of effort on a procedure and gauged by the time that the nurse-midwives needed to perform EIMC using AccuCirc (timed using a stopwatch plus video recording of each procedure), and the ability of nurse-midwives to safely perform the procedure. We considered 15 to 30 minutes a "feasible procedure time," based on the typical time spent in previous studies of the AccuCirc device., ${ }^{9,13}$

\section{Sample Size}

We chose a sample size of 500 subjects, as specified by the WHO "Framework for Clinical Evaluation of Devices for Male Circumcision."14 The rate of circumcision uptake was defined as the number of eligible male infants who were circumcised with AccuCirc, among those whose parents were asked to participate. With 500 infants undergoing EIMC, we could estimate a rate of 3\% severe AEs with 95\% confidence intervals (CIs) of $1.7 \%$ to $4.9 \%$, and could therefore exclude a severe AE rate of greater than $5 \%$.

\section{Statistical Analysis}

We used Stata 13 (StataCorp, TX, USA) to perform statistical analyses. We summarized characteristics of parents and infants, including socio-demographic characteristics, father's reported circumcision status, and circumcision and HIV knowledge and attitudes. To evaluate the safety of the procedure, we calculated the proportion of procedures associated with AEs and the associated 95\% CI. We calculated similar proportions and 95\% CIs for the parental acceptability outcomes. To assess feasibility, we calculated the mean time for the procedure and an associated 95\% CI.

\section{Ethical Considerations}

The Medical Research Council of Zimbabwe and the ethics committees of University College London and the London School of Hygiene and Tropical Medicine approved the study. We obtained written informed consent from the infant's mother and verbal consent from the infant's father (if available) before enrollment. After the procedure, mothers received a 20-liter plastic bucket, 2 bars of washing soap, a 100-ml bottle 
of Vaseline (for wound care), and 3 disposable diapers (total value US\$8). At each scheduled clinic visit, mothers also received the equivalent of US\$5 for bus fare.

\section{RESULTS}

\section{Participant Flow}

To enroll 500 infants in the field study, we approached 4,617 parents of newborn male infants.
Thus, the uptake rate was $11 \%(95 \% \mathrm{CI}, 10.1 \%$ to $11.9 \%)$. Some 4,107 parents (89\%) declined to participate. Reasons for refusal included fear of harm and sociocultural considerations. ${ }^{19}$ A further 10 male infants were excluded as ineligible (Figure). Between August 2013 and July 2014, 500 male infants ages 6 to 60 days were circumcised. The mother was in attendance during the procedure in $99.6 \%$ of cases. In the 2 instances when the mother was not there, the male infant's

FIGURE. Recruitment of Participants in the EIMC Field Study

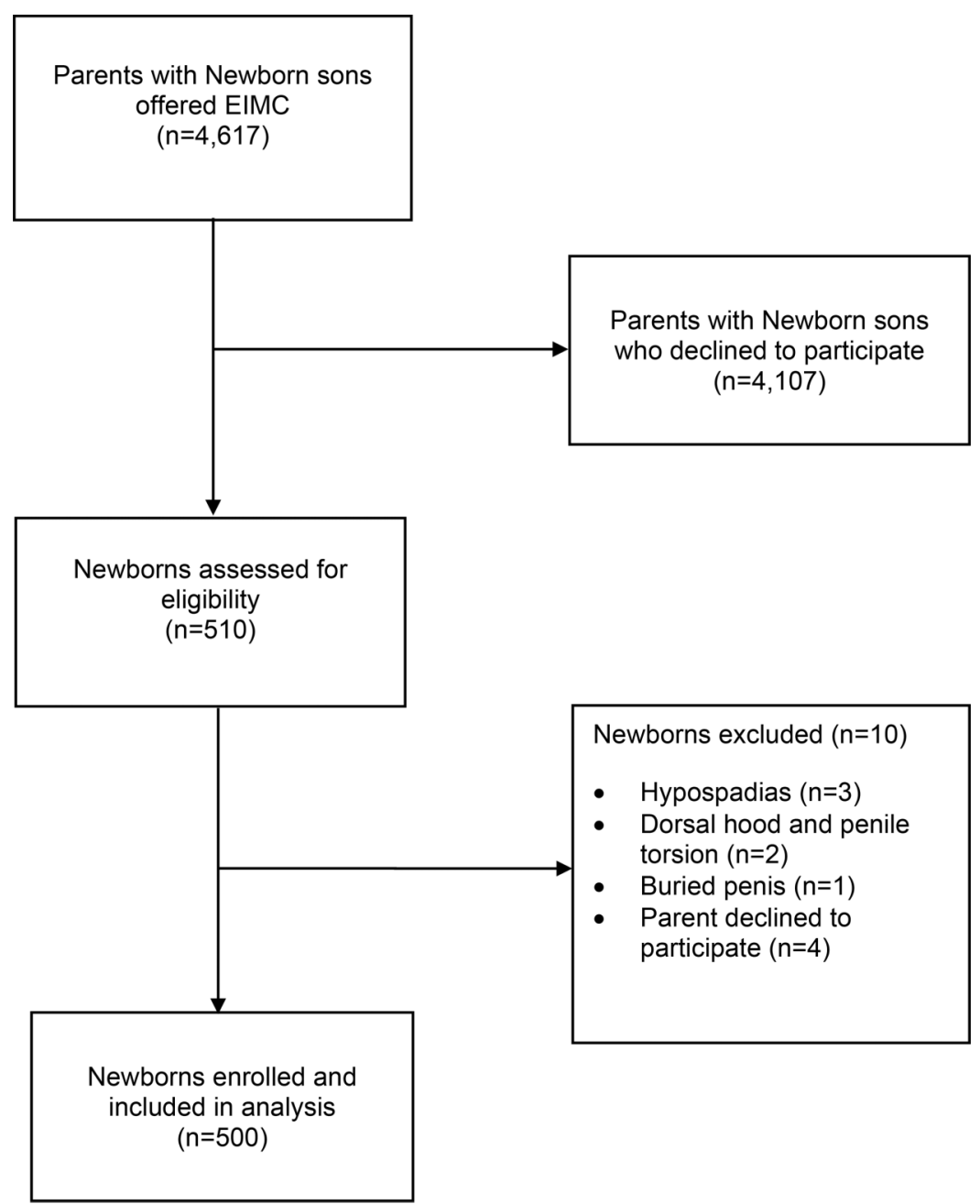

Abbreviation: EIMC, early infant male circumcision. 
father was present. Overall, fathers attended 34\% of the male infant circumcisions (Table 2). All but 1 participant (described in detail later) attended all 3 scheduled follow-up visits on days 2, 7, and 14 .

\section{Characteristics of Enrolled Infants and Their Mothers}

The median age of male infants at the time of circumcision was 22 days (interquartile range [IQR], 12 to 46 ) (Table 2). Eighty-five (17\%) of the infants were exposed to HIV. The median age of mothers was 28 years (IQR, 24 to 32 ). The majority of mothers were married $(n=478,96 \%)$, and more than half had completed secondary education $(n=295,59 \%)$. Approximately $40 \%$ of fathers were reportedly circumcised. Among mothers whose partner was not circumcised, $80 \%$ stated they would like him to be circumcised. Knowledge of circumcision was high among mothers who completed the study's quantitative questionnaire, with 431 (91\%) mothers reporting that they had heard of the preventive benefits of circumcision for HIV, and 393 (83\%) correctly stating that circumcision was partially protective against HIV. Some 185 mothers (40\%) felt that EIMC will likely be viewed positively in their community; 63 (13\%) said negatively; and $221(47 \%)$ said both ways. Even though they were largely satisfied by the procedure performed by nurse-midwives, a majority of mothers $(\mathrm{n}=433,92 \%)$ thought trained doctors should perform EIMC.

\section{Procedure Time and Intraoperative Events}

Completing the procedure took a median of 17 minutes (IQR, 15 to 18). Mild post-circumcision bleeding occurred in 49 male infants (10\%). For 46 of these infants (94\%), simple pressure stopped this bleeding. Three cases of bleeding could not be stopped by simple pressure. We classified these as moderate or severe procedurerelated AEs; we detail these cases below.

\section{Adverse Events}

We observed 7 AEs ( $1.4 \%$; $95 \%$ CI, $0.4 \%$ to $2.4 \%$ ) (Table 3 ). These included 2 cases of excessive removal of skin (moderate severity, requiring skin mobilization; wound completely healed 4 months post-EIMC in both cases) and 2 cases of inadequate skin removal (moderate severity; urologist concluded that neither required immediate corrective surgery), l case of moderate bleeding, and
2 cases of severe bleeding. There were no sequelae in any of the mild, moderate, or severe AE cases.

The 1 case of moderate bleeding required clamping of the bleeding vessel with forceps and an acetylated glucosamine dressing at the time of the procedure. The 2 cases of severe bleeding required hospitalization. In 1 case, the infant bled immediately post-circumcision. The bleeding was controlled with pressure but started again at home, and he was referred to a hospital. Three sutures were required to stem the bleeding. The other case of severe bleeding was in an infant who had a family history of hemophilia (unreported and undetected at the time of the procedure). The infant was given a blood transfusion $(200 \mathrm{ml})$. He was hospitalized for 3 days.

\section{Unrelated Newborn Death}

One male infant left the study 2 days after the procedure without any formal follow-up visits. This infant developed an acute respiratory infection after the procedure was performed and died 36 hours post-EIMC. The respiratory infection was due to an outbreak of severe bronchiolitis and was deemed unrelated to the EIMC procedure.

\section{Parental Satisfaction}

Approximately $40 \%$ of fathers were reportedly circumcised. Among mothers whose partner was not circumcised, $80 \%$ would like their partner to be circumcised.

All mothers who answered the question on satisfaction with EIMC $(n=498)$ reported being satisfied with the outcome ( scores $=6$ to 10), with $491(99 \%)$ reporting that they were very satisfied (scores $=8$ or greater). Nearly all mothers $(n=496$, 99\%) said they would recommend EIMC to other parents and would circumcise their next newborn son $(\mathrm{n}=497,99 \%)$. Among fathers who answered the question on satisfaction with EIMC, all 112 gave a score of 6 or greater. Nearly all the fathers would recommend the procedure to a friend $(\mathrm{n}=109,98 \%)$ and would have a future son circumcised $(\mathrm{n}=110,98 \%)$ (Table 3). The most common reason for dissatisfaction, cited by $5 \%$ of mothers and $8 \%$ of fathers, was the wound care requirements.

\section{DISCUSSION}

We have implemented the first field study in sub-Saharan Africa of EIMC conducted by nursemidwives using the AccuCirc device. We found that the procedure is safe, feasible, and acceptable to parents who choose it for their infant sons.

Overall, the rate of AEs was low and similar to those reported in the 2 previous AccuCirc studies

\author{
Moderate or \\ severe adverse \\ events occurred in \\ $\mathbf{7}$ of 500 \\ circumcisions.
}


TABLE 2. Characteristics of Infants and Mothers ( $N=500$ Infants and 500 Mothers)

\section{Characteristics and Views}

\section{Infants}

Age, days, median (IQR)

$22(12,46)$

Birth weight, $\mathrm{kg}$, median (IQR)

$3.2(2.9,3.5)$

Temperature, Celsius, median (IQR)

$36.2(36.0,36.5)$

Gestational age, weeks, median (IQR)

$40(38,40)$

Vitamin $\mathrm{K}$ given, No. (\%)

$500(100)$

HIV exposure status, ${ }^{a}$ No. (\%)

85 (17)

Mother present, ${ }^{\text {b }}$ No. (\%)

$498(99.6)$

Father present, No. (\%)

$168(34)$

\section{Mothers}

Mother's age, years, No. (\%)

$$
\leq 20
$$

$21-25$

$26-30$

$31-35$

$123(25)$

$>35$

Current marital status, No. (\%)

Married

$478(96)$

Not married

$21(4)$

Widowed

$1(0.2)$

With whom do you live?, ${ }^{\mathrm{C}}$ No. (\%)

Alone

Male partner

Other

Completed secondary level education?, No. (\%)

No

Yes

Ethnic group, No. (\%)

Shona

$406(81)$

Non-Shona 
Table 2. (continued).

\section{Characteristics and Views}

Head of household, ${ }^{d}$ No. (\%)

Mother

$28(6)$

Male partner

$431(91)$

Someone else

$14(3)$

Infant's father circumcised?, No. (\%)

Yes

No

$273(58)$

Don't know

HIV knowledge score, ${ }^{e}$ median (IQR)

Circumcision knowledge score, ${ }^{f}$ median (IQR)

Heard of male circumcision as an HIV prevention method before today, No. (\%)

Does male circumcision really protect men against HIV? , No. (\%)

Completely

Partially

No, it does not protect

Don't know

Would like male partner to be circumcised, 9 No. (\%)

Who should perform EIMC?, No. (\%)

Trained doctors

Trained nurse-midwives

Traditional leader of the same tribe or religion

Other

How will EIMC likely be viewed in community?, No. (\%)

Negatively

Positively

Both negatively and positively

$221(47)$

Abbreviations: EIMC, early infant male circumcision; IQR, interquartile range.

a HIV status unknown for 4 infants.

${ }^{b}$ In the 2 cases where the mother was not present, the infant's father was present during the procedure.

${ }^{c}$ Among the 22 not married or widowed mothers, 1 mother did not give an answer.

d Data collected from only 473 mothers.

e HIV knowledge score composed of 8 questions, with 1 point for every correct answer (maximum score $=8$ ).

${ }^{f}$ Circumcision knowledge score composed of 8 questions, with 1 point for every correct answer (maximum score $=8$ ).

g Among 273 mothers who reported their partner was not currently circumcised. 
TABLE 3. Adverse Events Associated With EIMC $(N=500)$, Time Taken for the Procedure, and Parental Satisfaction

\section{Outcome}

All AEs, No. (\%)

$7(1.4)$

Moderate/severe bleeding

$3(0.6)$

Infection

$0(0.0)$

Inadequate skin removal

$2(0.4)$

Excess skin removal

$2(0.4)$

Injury to penis

$0(0.0)$

Time taken to perform procedure, minutes, median (IQR)

$17(15,18)$

\section{Mothers' satisfaction ( $\left.\mathrm{N}=498^{\circ}\right)$}

Satisfaction score (0-10), No. (\%)

$$
0-5
$$

6-7

Reasons for dissatisfaction, No. (\%)

Appearance

Wound care requirements

Complication

Other reason

Mother would definitely recommend MC, ${ }^{b}$ No. (\%)

Mother would have a future son circumcised, No. (\%)

\section{Fathers' satisfaction ( $N=112)$}

Satisfaction score (0-10), No. (\%)

$$
0-4
$$

$5-6$

Reason for dissatisfaction, No. (\%)

Appearance

Wound care requirements 
Table 3. (continued).

\begin{tabular}{|c|c|}
\hline Outcome & \\
\hline Complication & $1(1)$ \\
\hline Other & $7(6)$ \\
\hline Father would definitely recommend $M C^{b}$, No. (\%) & $109(98)$ \\
\hline Father would have a future son circumcised, No. (\%) & $110(98)$ \\
\hline
\end{tabular}

conducted in Botswana ${ }^{9}$ and Zimbabwe. ${ }^{13}$ In both of these studies, doctors performed the circumcisions. The Botswana study identified 1 moderate $\mathrm{AE}(0.7 \% ; 95 \% \mathrm{CI}, 0.1 \%$ to $4.6 \%)$, and the Zimbabwe study identified 2 moderate AEs (2\%; $95 \%$ CI, $0.2 \%$ to $7.0 \%) .{ }^{9,13}$ Thus, our findings confirm previous findings that EIMC is a simple and safe procedure, characterized by a low rate of AEs. ${ }^{2,6,9,20,21}$ Moreover, AE rates were similar between the nurse-midwives in this study ( $1.4 \% ; 95 \% \mathrm{CI}, 0.4 \%$ to $2.4 \%$ ) and the doctors in the Zimbabwe study (2\%; $95 \%$ CI, $0.2 \%$ to $7.0 \%) .{ }^{13}$ This similarity suggests that it is both safe and feasible to roll out EIMC using nondoctor providers-a particularly important conclusion for sub-Saharan Africa, where nurses and midwives are in far greater supply than doctors. ${ }^{3,9,22}$ Despite accepting EIMC delivered by nurse-midwives, $92 \%$ of mothers thought that the procedure should be performed by trained doctors. Because this is a widespread preference, the need to educate parents on EIMC safety in the hands of nurse-midwives and other trained non-physician providers is a priority. ${ }^{23}$

Nonetheless, the fact that we encountered 2 cases of severe bleeding (including a case of unreported hemophilia) that required hospitalization for monitoring and management has important implications for EIMC planning and subsequent roll-out:

1. Although EIMC can be offered at the lowestlevel health facilities, there should be easily accessible backup services to deal with any life-threatening complications (e.g., excessive bleeding).

2. Intensive screening and history-taking before the procedure are required in order to exclude any infants with a family history of bleeding disorder.

3. Screening for other non-circumcision-related health issues is necessary to ensure that infants who are circumcised are clinically well.

The infant mortality rate is high in subSaharan Africa. Recent Zimbabwe Demographic and Health Survey findings suggest that infant and neonatal mortality rates are 57 and 31 deaths per 1,000 live births, respectively. ${ }^{24}$ Although the EIMC procedure itself is unlikely to result in major morbidity or mortality, it is important that babies who are unwell with other conditions are not circumcised. Such events may be mistakenly ascribed to EIMC. ${ }^{9}$ It will therefore be crucial to offer EIMC when all body systems are stable so that any immediate postpartum infant mortality is not erroneously ascribed to EIMC.

As in the Zimbabwe comparative trial, ${ }^{13}$ actual uptake of the procedure, at $11 \%$, was far lower than the $60 \%$ hypothetical acceptability that other studies had predicted. ${ }^{23,25}$ Previous studies in Zimbabwe and Zambia ${ }^{13,26}$ reported similar discrepancies. However, in both Zambia and Zimbabwe, EIMC was still offered in a research setting. The rate of EIMC uptake may differ when it is offered as part of an ongoing program. ${ }^{13}$ Zimbabwe is traditionally a non-circumcising country. It is to be expected that it will take time, and the program will need to earn the trust of parents, before EIMC - now an unfamiliar and perhaps scary procedure-becomes accepted. ${ }^{13}$ Nonetheless, culturally appropriate demand-creation activities to promote EIMC need to be conducted if EIMC is to become the norm. ${ }^{13}$

Sustained uptake and acceptability will depend greatly on perceptions of the safety and aesthetic aspects of EIMC. ${ }^{27}$ Encouragingly, in
Similar AE rates for physicians and nurse-midwives suggest that it is safe and feasible to roll out EIMC using nonphysician providers.

Actual uptake of the procedure$11 \%$-was lower than previously suggested by hypothetical acceptability studies. 
this field study nearly all mothers (99\%) reported high satisfaction with the outcome. These findings are consistent with others from the region (Botswana, Kenya, and Zambia), which report levels of satisfaction over $90 \% .{ }^{6,10,28}$ With specific reference to satisfaction with EIMC performed via AccuCirc, the findings are consistent with those from our comparative trial and from Botswana, where over $91 \%$ of mothers reported high or

It may be possible to use EIMC as a platform to strengthen other maternal and child health programs and to promote other health interventions to men. complete satisfaction with the outcome. ${ }^{9,13}$ To maintain these high levels of satisfaction, EIMC provision will need to be carefully monitored and supervised to ensure that AEs are minimized and appropriately managed. ${ }^{23}$ As with most selfreported data, the high levels of satisfaction could be due to social desirability bias. However, after qualitatively exploring this issue ${ }^{29}$ and triangulating findings from different data collection approaches, we can safely conclude that the reported levels of satisfaction are a true reflection of what parents actually felt.

Most women who sought EIMC for their sons were knowledgeable about male circumcision and its HIV-preventive benefits. Our findings corroborate those from previous studies on the hypothetical acceptability of VMMC and EIMC; these studies found that this knowledge is likely to be associated with uptake. ${ }^{23,30}$ Widespread awareness campaigns to enhance men's and women's knowledge of male circumcision and its benefits will be essential for successful scale-up. Furthermore, about $40 \%$ of women who sought EIMC for their sons reported that the infant's father was circumcised, whereas the prevalence of male circumcision in the general male population is estimated to be around $10 \%{ }^{24}$ This suggests that, as adult VMMC spreads, demand for EIMC is likely to grow.

A few women $(n=63,13 \%)$ felt that EIMC will likely be viewed negatively in their community. Hypothetical acceptability studies have suggested that fear of their son's future social exclusion, including ostracism, derision, and rejection, may discourage parents from opting for EIMC. ${ }^{30-32}$ Current initiatives that portray VMMC as a lifestyle choice for a man who is clean, elegant, and confident are likely playing a critical role in changing community norms about the procedure. ${ }^{33}$ In addition, uptake of VMMC in Zimbabwe continues to rise (from 10,000 in 2009 to 600,000 as of December 2015); community norms are also likely to change as more men opt for circumcision.
EIMC may provide a rare opportunity to reach fathers via health care facilities. In this study, for example, about one-third of fathers accompanied their sons to the EIMC clinic. Otherwise, men are known to be hard to reach via health services. ${ }^{34-36}$ Additionally, men in general, and Zimbabwean men specifically, rarely accompany their wives to the clinic for antenatal or infant care. But it may be possible to use EIMC as a platform to strengthen other maternal, newborn, and child health programs and to promote other health interventions to men, such as VMMC and prevention of mother-to-child transmission of HIV.

\section{Limitations}

The sample size of this field study was guided by the WHO "Framework for Clinical Evaluation of Devices for Male Circumcision, ${ }^{\prime 14}$ but the number was nonetheless small. Thus, it is possible that we did not detect all potential AEs that might occur during EIMC roll-out. Field studies of the AccuCirc device currently under way in Kenya will increase our knowledge of AEs associated with the procedure. We also studied EIMC only in an urban setting. Findings, particularly on acceptability, might be different in rural areas. Similar research needs to take place in a different setting in order to further inform EIMC programming and roll-out.

\section{CONCLUSIONS}

We circumcised 500 male infants in a field study of the AccuCirc device for EIMC in Zimbabwe. We found that EIMC can be safely and acceptably offered by nurse-midwives using the AccuCirc device. The AccuCirc device has the potential to facilitate widespread scale-up of safe EIMC in sub-Saharan Africa.

Acknowledgments: We thank study participants, their parents, and their extended families for making this study possible. We also thank Harare City Health for granting us the permission to conduct this study at the Edith Opperman and Mabvuku clinics, Harare. The Bill \& Melinda Gates Foundation funded this study through Population Services International (PSI). The content of this article is solely the responsibility of the authors and does not necessarily represent the official views of the Gates Foundation or PSI.

Competing Interest: None declared.

\section{REFERENCES}

1. Binagwaho A, Pegurri E, Muita J, Bertozzi S. Male circumcision at different ages in Rwanda: a cost-effectiveness study. PLoS Med. 2010;7(1):e1000211. CrossRef. Medline 
2. Kalichman SC. Neonatal circumcision for HIV prevention: cost, culture, and behavioral considerations. PLoS Med. 2010;7(1): e1000219. CrossRef. Medline

3. Mangenah C, Marhu W, Hatzold K, Biddle AK, Madidi N, Ncube $G$, et al. Estimating the cost of early infant male circumcision in Zimbabwe: results from a randomized noninferiority trial of AccuCirc device versus Mogen clamp. J Acquir Immune Defic Syndr. 2015;69(5):560-566. CrossRef. Medline

4. Plank RM, Makhema J, Kebaabetswe P, Hussein F, Lesetedi C, Halperin $D$, et al. Acceptability of infant male circumcision as part of HIV prevention and male reproductive health efforts in Gaborone, Botswana, and surrounding areas. AIDS Behav. 2010;14(5):1198-1202. CrossRef. Medline

5. World Health Organization (WHO); Jhpiego. Manual for early infant male circumcision under local anaesthesia. Geneva: WHO; 2011 . Available from: http://www.who.int/hiv/pub/ malecircumcision/manual_infant/en/

6. Young MR, Bailey RC, Odoyo-June E, Irwin TE, Obiero W, Ongong'a DO, et al. Safety of over twelve hundred infant male circumcisions using the Mogen clamp in Kenya. PLoS One. 2012;7(10):e47395. CrossRef. Medline

7. Sherman J, Borer JG, Horowitz M, Glassberg KI. Circumcision: successful glanular reconstruction and survival following traumatic amputation. J Urol. 1996;156(2 P+ 2):842-844. Medline

8. Patel HI, Moriarty KP, Brisson PA, Feins NR. Genitourinary injuries in the newborn. J Pediatr Surg. 2001;36(1):235-239. Medline

9. Plank RM, Wirth KE, Ndubuka NO, Abdullahi R, Nkagu M, Lesetedi $C$, et al. Single-arm evaluation of the AccuCirc device for early infant male circumcision in Botswana. J Acquir Immune Defic Syndr. 2014;66(1):1-6. CrossRef. Medline

10. Plank RM, Ndubuka NO, Wirth KE, Mwambona JT, Kebaabetswe P, Bassil B, et al. A randomized trial of Mogen clamp versus Plastibell for neonatal male circumcision in Botswana. J Acquir Immune Defic Syndr. 2013;62(5): e131-e137. CrossRef. Medline

11. Bode $\mathrm{CO}$, Ikhisemojie $\mathrm{S}$, Ademuyiwa $\mathrm{AO}$. Penile injuries from proximal migration of the Plastibell circumcision ring. J Pediatr Urol. 2010;6(1):23-27. CrossRef. Medline

12. Gee WF, Ansell JS. Neonatal circumcision: a ten-year overview: with comparison of the Gomco clamp and the Plastibell device. Pediatrics. 1976;58(6):824-827. Medline

13. Marhu W, Larke N, Hatzold K, Ncube G, Weiss HA, Mangenah $C$, et al. Implementation and operational research: a randomized noninferiority trial of AccuCirc device versus Mogen clamp for early infant male circumcision in Zimbabwe. J Acquir Immune Defic Syndr. 2015;69(5):e156-e163. CrossRef. Medline

14. World Health Organization (WHO); Joint United Nations Programme on HIV/AIDS (UNAIDS). Framework for clinical evaluation of devices for male circumcision. Geneva: WHO; 2010. Available from: http://www.who.int/hiv/pub/ malecircumcision/framework/en/

15. Harare City Health Department. Report on the City Health Department. Harare (Zimbabwe): Harare City Health Department; 2010.

16. Blass EM, Hoffmeyer LB. Sucrose as an analgesic for newborn infants. Pediatrics. 1991;87(2):215-218. Medline

17. Taddio A. Pain management for neonatal circumcision. Paediatr Drugs. 2001;3(2):101-111. CrossRef. Medline

18. Brady-Fryer B, Wiebe N, Lander JA. Pain relief for neonatal circumcision. Cochrane Database Syst Rev. 2004;(4): CD004217. Medline
19. Marhu W. Feasibility and acceptability of early infant male circumcision as an HIV prevention intervention in Zimbabwe [Doctoral Thesis]. London: University College London, Research Department of Infection \& Population Health; 2014. Available from: http://discovery.ucl.ac.uk/1449524/

20. Wiswell TE, Geschke DW. Risks from circumcision during the first month of life compared with those for uncircumcised boys. Pediatrics. 1989;83(6):1011-1015. Medline

21. El Bcheraoui C, Zhang X, Cooper CS, Rose CE, Kilmarx PH, Chen RT. Rates of adverse events associated with male circumcision in US medical settings, 2001 to 2010. JAMA Pediatr. 2014;168(7): 625-634. CrossRef. Medline

22. World Health Organization (WHO). The world health report 2006: working together for health. Geneva: WHO; 2006. Available from: http://www.who.int/whr/2006/en/

23. Mavhu W, Hatzold K, Laver SM, Sherman J, Tengende BR, Mangenah C, et al. Acceptability of early infant male circumcision as an HIV prevention intervention in Zimbabwe: a qualitative perspective. PLoS One. 2012;7(2):e32475. CrossRef. Medline

24. Zimbabwe National Statistics Agency (ZIMSTAT); ICF International. Zimbabwe demographic and health survey 2010-11. Calverton (MD): ICF International; 2012. Co-published by ZIMSTAT. Available from: hitps://dhsprogram.com/pubs/ pdf/FR254/FR254.pdf

25. Mavhu W, Buzdugan R, Langhaug LF, Hatzold K, Benedikt C, Sherman J, et al. Prevalence and factors associated with knowledge of and willingness for male circumcision in rural Zimbabwe. Trop Med Int Health. 2011 ; 16(5):589-597. CrossRef. Medline

26. Waters E, Li M, Mugisa B, Bowa K, Linyama D, Stringer E, et al. Acceptability and uptake of neonatal male circumcision in Lusaka, Zambia. AIDS Behav. 2013;17(6):2114-21 22. CrossRef. Medline

27. Westercamp N, Bailey RC. Acceptability of male circumcision for prevention of HIV/AIDS in sub-Saharan Africa: a review. AIDS Behav. 2007;11(3): 341-355. CrossRef. Medline

28. Bowa K, Li MS, Mugisa B, Waters E, Linyama DM, Chi BH, et al. A controlled trial of three methods for neonatal circumcision in Lusaka, Zambia. J Acquir Immune Defic Syndr. 2013;62(1): e1-e6. CrossRef. Medline

29. Marhu W, Hatzold K, Ncube G, Fernando S, Mangenah C, Chatora K, et al. Perspectives of parents and health care workers on early infant male circumcision conducted using devices: qualitative findings from Harare, Zimbabwe. Glob Health Sci Pract. 2016;4 Suppl 1:S55-S67. CrossRef

30. Mavhu W, Mupambireyi Z, Hart G, Cowan FM. Factors associated with parental non-adoption of infant male circumcision for HIV prevention in Sub-Saharan Africa: a systematic review and thematic synthesis. AIDS Behav. 2014; 18(9):1776-1784. CrossRef. Medline

31. Bailey RC, Muga R, Poulussen R, Abicht H. The acceptability of male circumcision to reduce HIV infections in Nyanza Province, Kenya. AIDS Care. 2002;14(1):27-40. CrossRef. Medline

32. Ngalande RC, Levy J, Kapondo CPN, Bailey RC. Acceptability of male circumcision for prevention of HIV infection in Malawi. AIDS Behav. 2006;10(4):377-385. CrossRef. Medline

33. Hatzold K, Marhu W, Jasi P, Chatora K, Cowan FM, Taruberekera N, et al. Barriers and motivators to voluntary medical male circumcision uptake among different age groups of men in Zimbabwe: results from a mixed methods study. PLoS One. 2014;9(5):e85051. CrossRef. Medline

34. Chirawu P, Langhaug L, Mavhu W, Pascoe S, Dirawo J, Cowan F. Acceptability and challenges of implementing voluntary 
counselling and testing (VCT) in rural Zimbabwe: evidence from the Regai Dzive Shiri Project. AIDS Care. 2010;22(1):81-88. CrossRef. Medline

35. Mavhu W, Dauya E, Bandason T, Munyati S, Cowan FM, Hart G, et al. Chronic cough and its association with TB-HIV co-infection: factors affecting help-seeking behaviour in Harare,
Zimbabwe. Trop Med Int Health. 2010;15(5):574-579 CrossRef. Medline

36. Skovdal M, Campbell C, Madanhire C, Mupambireyi Z, Nyamukapa C, Gregson S. Masculinity as a barrier to men's use of HIV services in Zimbabwe. Global Health. $2011 ; 7(1): 13$. CrossRef. Medline

\section{Peer Reviewed}

Received: 2015 Jul 2; Accepted: 2016 Mar 17

Cite this article as: Marhu W, Larke N, Hatzold K, Ncube G, Weiss HA, Mangenah C, et al. Safety, acceptability, and feasibility of early infant male circumcision conducted by nurse-midwives using the AccuCirc device: results of a field study in Zimbabwe. Glob Health Sci Pract. 2016; 4 Suppl 1:S42-S54. http://dx.doi.org/10.9745/GHSP-D-15-00199

(c) Mavhu et al. This is an open-access article distributed under the terms of the Creative Commons Attribution License, which permits unrestricted use, distribution, and reproduction in any medium, provided the original author and source are properly cited. To view a copy of the license, visit $\mathrm{http}: / /$ creativecommons.org/licenses/by/3.0/. When linking to this article, please use the following permanent link: http://dx.doi.org/ 10.9745/GHSP-D-15-00199 